Logos Universality Mentality Education Novelty, Section: Social Sciences

ISSN: $2284-5747$ (print), ISSN: $2284-5747$

(electronic)

Covered in: CEEOL, Index Copernicus, Ideas

RePeC, EconPapers, Socionet

\title{
AMBIGUITY TOLERANCE IN PRODUCTIONAL CREATIVITY
}

Beatrice Adriana BALGIU

Logos Universality Mentality Education Novelty, Section:

Social Sciences, 2014, Year III, Issue 1, pp: 29-40

Published by:

Lumen Publishing House

On behalf of:

Lumen Research Center in Social and Humanistic Sciences 


\title{
Ambiguity Tolerance in Productional Creativity
}

\author{
Beatrice Adriana BALGIU ${ }^{1}$
}

\begin{abstract}
Ambiguity tolerance consists in the "ability to live" with ambiguity to cope with the stimuli or with the situations which are not clearly structured, which are new and complex. The analysis of ambiguity tolerance in the studies on creativity has become relatively important lately. The objective of present research was to analyze the ambiguity tolerance in the potential and productional creativity. In these conditions, creativity was measured by a test of potential creative thinking, on the one hand, and creativity tasks consisting in demand for building logotexts, on the other hand.

The results show that there is a positive correlation between ambiguity tolerance and creativity, the important contribution having the ideational fluency and flexibility in both cases. We can consider that the more individuals tolerate ambiguity, the greater their creative potential and the more they will show it in their creative productions.
\end{abstract}

\section{Keywords:}

ambiguity tolerance, creativity, creative construction tasks, students, logos

1 Associate Professor, Politehnica University of Bucharest, Romania, beatricebalgiu@yahoo.com, beatrice.balgiu@upb.ro. 


\section{Introduction}

The analysis of ambiguity tolerance in the studies on creativity has become relatively important lately. The latter was examined in association with various psychological variables such as creative motivation and the need for achievement (Stoycheva, 2008), intrinsic motivation (Urban, 2003), risk-taking (Lauriola \& Levin, 2001), with the personality factors in the Big Five model (McCulloch, Kaul, Wagstaff \& Wheatcroft, 2005), as well as with phenomena such as organizational behaviour (Judge, Thoresen, Pucik \& Welbourne, 1999), academic achievement (Boyd, Hunt, Kandell \& Lucas, 2003), academic leadership (Kajs \& McCollum, 2009) and even the propensity to cheat during exams (Thompson, Austin \& Walters, 2004).

As expected, the most frequent studies highlighted and confirmed the association between ambiguity tolerance and potential creativity measured by means of questionnaires and divergent thinking tests (Vernon, 1970; Sternberg \& Lubart, 1995; Durheim \& Foster, 1997; Stoycheva, 2003). However, there are very few studies on the relation between ambiguity tolerance and the production of ideas. We will refer to the latter in the following lines. A review study on the relationship between ambiguity tolerance and creativity found in the work of Furnham \& Marks (2013).

\section{Ambiguity tolerance in the production of ideas}

Ambiguity tolerance (AT) consists in the "ability to live" with ambiguity (Stoycheva, 2003), to cope with the stimuli or with the situations which are not clearly structured, which are new and complex (Radant, 2008). The individuals who do not tolerate ambiguity perceive and interpret ambiguous situations as a source of psychological discomfort and they tend to avoid the latter. In addition, they experiment intense negative affectivity such as stress and anxiety. The individuals who are more tolerant to ambiguity have the ability to tolerate feelings of anxiety and uncertainty. The affective reactions are less intense and varied. They perceive and interpret an ambiguous situation more adequately, more realistically, without distorting the complexity of problems.

While the studies on the relation between ambiguity tolerance (AT) and potential creativity measured by means of tests are in agreement with one another and shed some light on the importance of AT in creativity, there is little research on the association between $\mathrm{AT}$ and the activity of individuals in creative solution tasks; this may be due to some procedures which are more difficult than the application and quantification of questionnaires, inventories etc. 
One such major research was conducted by Comadena (1984) who examined the creative performance of 76 graduates during brainstorming sessions and who observed that there was a positive relation between ambiguity tolerance and the number of generated ideas.

In a different context, Zenasni, Besancon and Lubart (2008) used three methods of measuring creativity for a sample of 68 subjects (34 teenagers and 34 parents): the provision of as many titles as possible in the case of some ambiguous stimuli, the writing of stories based on ambiguous stimuli and the application of a self-assessment scale for creative personality. Results showed that AT is related to fluency and uniqueness and, to a smaller extent, to originality. Individuals' ability to tolerate ambiguity is related to the ability to generate unique and original ideas and to produce creative stories.

After researching on the relation between teenagers' AT and creative performance, Stoycheva (2009) concluded that subjects with high AT generate ideas and solutions which are more original and titles which are less descriptive and more abstract in verbal and nonverbal tasks in Torrance tests in comparison with the subjects with low AT. In another experimental study (Stoycheva, Popova \& Komneva, 2007) on the impact of redefining problems in the generation of creative solutions, two groups of business administration students were asked to generate original and efficient solutions for real life problems. Psychologists assessed the redefinition of problem, while experimented managers assessed the creativity of solutions proposed for the problems. Individual differences in AT were related to the redefinition of problems and creativity. The subjects with high AT proceeded to redefinitions of problems subsequently assessed as larger and more generalized, and the creativity score of the solutions in the case of redefined problems was higher than the score in the case of the problems which were not redefined.

We also present a piece of research whose objective was the investigation of the relationship between ambiguity tolerance, the personality traits measured by means of questionnaires based on the Big Five model, and ideational creativity evaluated by means of brainstorming (Balgiu, 2012). For this, four fifty-minute brainstorming sessions were used in the case of 52 students. The method of brainstorming, conceived as a method of creating stimulation, was used in this case in order to make students solve heuristic tasks in order to evaluate the respective subjects' creativity with it.

Starting from the results mentioned above, we find it important to test the relation between $\mathrm{AT}$ and creativity by means of measurements which include productional originality. 


\section{Method}

Objective: 1. The evaluation of AT within a group of engineering students; 2. The analysis of the relationship between AT and productional creativity using as creativity indicators both a creativity test and a new method of assessing creativity: creative construction tasks. We try to replicate the results with new measurements within a new sample.

Hypothesis: the relation between AT and potential creativity is consonant with the implication of $\mathrm{AT}$ in product creativity.

Subjects: 210 technical students (74 girls and 136 boys) from years II IV of the Polytechnica University of Bucharest - the largest state technical university from Romania. The age average of the sample is: $\mathrm{M}=20,41$ S.D. $=$ 1,45 . The participants study technical creativity (the exact name of the course in the Romanian language is Psychoinventics) and Engineering Graphics. The tests below were applied during the seminar classes of the respective courses. The students were not given any material reward for the completion of questionnaires. All participants received the questionnaires in paper-and-pencil version.

\section{Instruments:}

1. Scale of ambiguity tolerance (Nutt, 1988) created by adapting Budner's 1962 AT scale. The scale is made of 16 items evaluated in seven stages, from 1 - totally disagree to 7 - totally agree. 8 items are evaluated in reverse. Examples of items: An expert who does not give a definitive answer probably does not know that much; Teachers or supervisors who hand out vague assignments give one a chance to show initiative and originality. According to Nutt (1988), this test has good characteristics of measurement, and it demonstrates a quotient of internal consistency of 0,86 within the samples used.

In order to measure creativity and its parameters, we used the following two modalities:

2. The creativity test entitled "Unusual Usages" elaborated and standardized by Stoica-Constantin \& Caluschi (1989 and revised 2006) on a Romanian population in order to measure potential creative thinking ( $\alpha=$ $0,89)$. The test consists in discovering as many usages as possible for an ordinary cane with a spike at the lower end. The test lasts for 5 minutes (determined by the test authors). Creativity is summarized by its three dimensions, fluency (the total number of ideas), flexibility (the passage from one category of items to another) and originality (calculated by checking every answer against the list of items evaluated by means of a scale from 0 (banal) to 13 , where 13 is the minimal frequency of appearance, therefore, a high degree of originality. Finally, we add the originality scores for all the answers, thus, obtaining a score at this factor per test). The gross scores for the three 
dimensions are turned into a standard score on the progressive scale of 1 to 9 . Our prior experience with the respective test makes us believe that it is mainly based on the assessment of great creative force. We believe that the test addresses the intellectual component of creativity and, at the same time, creative attitudes such as restructuring day-to-day life, focusing on risk, the sense of humor (the request to name less ordinary usages urges the subject to do away with common, stereotypical images).

3. Creative construction tasks. The tasks were created starting from the definitions proposed by Lubart (1994) and Amabile (1996), according to whom a creative task is an open-ended solving process adapted to the abilities of participants and guided under restrictions. This type of tasks can be used for individuals' assessment.

Task no. 1 for verbal creativity with graphical support. Thus, the subjects were asked to create logo texts for three graphical representations considered significant for life situations, such as a microphone in a radio station, a funerary car and a car service. These situations were chosen as they are considered to have a large coverage in the social life of the community. The subjects were instructed to create as many logos as possible, logos that should be different from those that other people could propose;

- Task no. 2 is created for verbal creativity in the absence of the visual support. The subjects were asked to create titles for a commercial for a courier service. The time limit for completion was 30 minutes in the first case and 10 minutes in the second.

In order to measure performance we examined the fluency of ideas (the number of relevant ideas), flexibility (the categories of answer), and originality (the rarity of ideas). The latter was analyzed by two evaluators by means of the inter-subjective technique which focuses on the subjective appraisal of the original products. The two evaluators assessed the logo-texts independently on a scale from 1 to $7: 1-$ banal, 7 - very original. The consensuality of the interevaluators was calculated and it was satisfactory $\dot{\alpha}=69$ for task no. $1, \dot{\alpha}=58$ for task no. 2. Finally, the average of the marks given by the evaluators was calculated. For task 1, which contains in fact three subtasks, we added the scores for the dimensions of fluency, flexibility and originality within the three subtasks.

Procedure: The participants are students in the course of technical creativity (the precise title of the course in the Romanian language is Psihoinventica) and Engineering Graphics. The tests below were applied during the seminar classes of the respective courses. The subjects were not given any material compensation for filling in the questionnaires. AT tests and creativity tests were applied at the beginning of the course; towards the end of the course, 
approximately two months later, the second method of measuring creativity was applied. All the tests were applied collectively.

Apart from the primary analysis used for gathering the results specific to the category of examined subjects, we used correlational analysis (a Pearson correlation matrix). The data of the research were processed with the STATISTICA software.

\section{Results and discussions}

\subsection{Levels and significations of general data}

As table no.1 shows, the group of subjects analyzed is characterized by moderated AT $(\mathrm{M}=57,87$ S.D. = 7,87). We can state that the respective students have a moderate reaction to ambiguous stimuli and they adapt to the latter with an acceptable speed.

To the extent to which one can compare groups of youths from different countries and having some reservations with respect to the generalization of results, one can infer that the AT of the students who participated in the present study is more reduced than that of the American engineering students investigated by means of AT Budner scale (the latter present $\mathrm{M}=48,9$ apud Aven, De Vries, Williams \& Smith, 2002) and even that of those in library science $(M=29,82$, S.D. $=10,16-$ Helmick, 1982) and medicine (Sherrill, 2001). This seems plausible if we refer back to the original standard test created by Nutt (1988) and Johns (1998) where $\mathrm{M}=45,00$. The difference between the Romanian and the American norm can be also explained by the asymmetry between the number of men and women in the present sample (the prevalence of males is specific to technical universities in Romania). We have not achieved gender differences in this regard. 


\section{Table 1}

\section{Averages and standard deviations}

\begin{tabular}{|l|l|l|l|l|}
\hline Variables & Means & Min. & Max. & S.D. \\
\hline $\begin{array}{l}\text { Tolerance of } \\
\text { ambiguity }\end{array}$ & 57,87 & 37 & 77 & 7,87 \\
\hline Creativity test & \multicolumn{5}{|l|}{} \\
\hline Fluency & 5,69 & 2 & 9 & 1,88 \\
\hline Flexibility & 6,36 & 2 & 9 & 1,80 \\
\hline Originality & 4,94 & 1 & 9 & 1,86 \\
\hline Creativity & 5,66 & 2 & 9 & 1,86 \\
\hline Task 1 & \multicolumn{5}{|l|}{} \\
\hline Fluency & 7,96 & 1 & 22 & 4,94 \\
\hline Flexibility & 7,71 & 1 & 20 & 4,67 \\
\hline Originality & 25,70 & 1 & 95 & 17,77 \\
\hline Task 2 & \multicolumn{5}{|l}{} \\
\hline Fluency & 4,39 & 1 & 13 & 2,81 \\
\hline Flexibility & 4,10 & 1 & 11 & 2,64 \\
\hline Originality & 13,42 & 1 & 49 & 9,33 \\
\hline
\end{tabular}

The averages for the creative potential are shown in table no. 1 at the level of standard scores (Creativity test). Originality and creativity are moderate (class 5 and 6 from scale of 1 to 9). There is also moderate creativity (expressed by the 4 parameters) obtained in the case of both creativity tasks, which, possibly, prevails over low correlations in terms of number and intensity.

Some of the logos considered to have high originality ( $\mathrm{M}$ between 5,75 - 7,75) are: For the courier service - Fast, faster and faster. Fan Curier; Faster than optic fiber; We do away with borders; Packages under one kilo are delivered in the solar system for free. We are not fast, it is just that the others are slow. For the car service - Beauty spa for your car; Our deliveries are gone with the wind; Nothing gets damaged, everything gets fixed; For the funerary car - We redefine space and comfort for ever; The last five-star journey; Next to you until the end; For the radio - A radio that leads a world in movement, Stop singing in the shower! Make yourself known!; Your voice, your dream, our studio; In the beginning was the word, wasn't it?

\subsection{The comparative analysis of intercorrelations}

Table no. 2 shows the intercorrelation of variables. We obtained consistent correlations between the parameters of the methods of measuring creativity (creativity test, task 1 and task 2) and between the parameters of the two tasks which measure creativity by creating logos. There is a reduced 
number of correlations (three) between potential creativity and creativity measured from a productional point of view.

In addition, the factorial analysis has shown a two-factor solution (Varimax row) which comprises, on the one hand, the variables of fluency, flexibility, originality and creativity evaluated by means of the test of potential creativity (variance $=3,99$, proportion $=.21$ ), and, on the other hand, factor no. 2 shows a load with the fluency, the uniqueness and the originality evaluated by means of the task of creating logos in the case of task no. 1 ( with a visual support $)-$ variance $=9,10$, proportion $=.47$. This result suggests that the two measures address some partially distinct aspects of creativity.

Table 2

The intercorrelation of variables

\begin{tabular}{|l|l|l|l|l|l|l|l|l|l|l|l|}
\hline Variables & $\mathbf{1}$ & $\mathbf{2}$ & $\mathbf{3}$ & $\mathbf{4}$ & $\mathbf{5}$ & $\mathbf{6}$ & $\mathbf{7}$ & $\mathbf{8}$ & $\mathbf{9}$ & $\mathbf{1 0}$ & $\mathbf{1 1}$ \\
\hline $\begin{array}{l}\text { 1. Tolerance } \\
\text { of ambiguity }\end{array}$ & $\mathbf{1}$ & & & & & & & & & & \\
\hline $\begin{array}{l}2 . \quad \text { Fluency } \\
\text { (creativity test) }\end{array}$ & 13 & $\mathbf{1}$ & & & & & & & & & \\
\hline $\begin{array}{l}\text { 3. Flexibility } \\
\text { (creativity test) }\end{array}$ & 10 & $76^{*}$ & $\mathbf{1}$ & & & & & & & & \\
\hline $\begin{array}{l}4 . \quad \text { Originality } \\
\text { (creativity test) }\end{array}$ & $17^{*}$ & $82^{*}$ & $65^{*}$ & $\mathbf{1}$ & & & & & & & \\
\hline $\begin{array}{l}\text { 5. Creativity } \\
\text { (creativity test) }\end{array}$ & $14^{*}$ & $78^{*}$ & $56^{*}$ & $69^{*}$ & $\mathbf{1}$ & & & & & & \\
\hline $\begin{array}{l}\text { 6. Fluency } \\
\text { (task 1) }\end{array}$ & $25^{*}$ & 21 & 15 & 24 & 26 & $\mathbf{1}$ & & & & & \\
\hline $\begin{array}{l}\text { 7. Flexibility } \\
\text { (task 1) }\end{array}$ & $25^{*}$ & 19 & 13 & 22 & 24 & $99^{*}$ & $\mathbf{1}$ & & & & \\
\hline $\begin{array}{l}\text { 8. Originality } \\
\text { (task 1) }\end{array}$ & 16 & $29^{*}$ & 24 & $31^{*}$ & $32^{*}$ & $81^{*}$ & $81^{*}$ & 1 & & & \\
\hline $\begin{array}{l}\text { 9.Fluency } \\
\text { (task 2) }\end{array}$ & $23^{*}$ & -07 & -08 & -01 & 00 & $69^{*}$ & $71^{*}$ & $63^{*}$ & $\mathbf{1}$ & & \\
\hline $\begin{array}{l}10 . \quad \text { Flexibility } \\
\text { (task 2) }\end{array}$ & $19^{*}$ & 03 & 04 & 08 & 08 & $69^{*}$ & $70^{*}$ & $65^{*}$ & $98^{*}$ & $\mathbf{1}$ & \\
\hline $\begin{array}{l}11 . \text { Originality } \\
\text { (task 2) }\end{array}$ & 17 & 09 & 13 & 16 & 14 & $60^{*}$ & $61^{*}$ & $67^{*}$ & $84^{*}$ & $.88^{*}$ & $\mathbf{1}$ \\
\hline
\end{tabular}

Further on, the correlational analysis shows the fact that $\mathrm{AT}$ is poorly, but significantly linked to originality $(\mathrm{r}=.17)$ and potential creativity $(\mathrm{r}=.14)$. We obtained moderate significant positive correlations between AT and the fluidity and the flexibility within tasks 1 and 2 (coefficient between 19 and 25). The relationship between AT and originality is not obvious and does not reach $\mathrm{p}<.01$. Although flexibility is quite strongly linked to originality, this difference between results can reflect the difference of cognitive strategies in different 
tasks. Creating logos entails a developed lexis and working with metaphors; from a cognitive point of view, it involves making analogies and working with terms and signs of a polysemantic nature subjected to several types of possible interpretations. As Heilbrun (2002) shows, creating a logo entails intelligence, creativity, intuition, and vision in order to communicate something in a concentrated verbal representation. On the other hand, the relationship between TA and originality is not always clarified and stated. For example, when they used the measurement of creativity by writing stories in the case of a sample of teenagers, Zenasni et al (2008) did not find correlations between AT and originality; they found correlations between inambiguity tolerance and uniqueness of ideas instead.

The result we obtained with respect to the relation between AT and the number of ideas as well as between AT and flexibility corroborates other pieces of research (Comadena, 1984; Pürto, 2004; Stoycheva, 2008; Zenasni et al., 2008). Taking into consideration the results, we can conclude that the more tolerant of ambiguity individuals are, the more ideas from various categories will be generated. If this is true at a potential level, it will probably also be true when the subjects in cause are put in the situation to show creativity. In other words, individuals with AT show this feature irrespective of the situation. We can consider that a high AT would allow individuals to show their creative potential.

\section{Conclusions}

In general, the studies on the relation between TA and creativity used measures of potential creativity rather than of creative performance. In the present study we proposed the analysis of the relation between ambiguity tolerance and productional creativity. The subjects, who are engineering students, were asked to create logo texts for given situations and images. They also took a test of verbal creativity calibrated to the level of the Romanian population. The global results show a positive, though moderately intense relation between ambiguity tolerance, the number of ideas and originality. Therefore, the more individuals are tolerant to ambiguity, the more they will generate more original logos. We can draw the conclusion that the more tolerant to ambiguity individuals are, the more they will manifest their creative potential in original results. The study is consistent with other previous pieces of work which found that AT is positively linked to a series of indicators of the creative behavior. In the study we have the validity of the relation between creativity and AT in the case of creativity measurement.

We consider that one of the limits of the study is the usage of some concrete graphical representations in creative tasks. For such a study, it would have been more appropriate to use creative construction tasks based on the 
generation of new ideas for ambiguous stimuli, which can be interpreted in multiple ways. The conclusion to be drawn for future research is that the types of tasks and/or activities need to be modified so that they should contain ambiguous stimuli.

\section{REFERENCES}

Amabile, T. (1996). Creativitatea ca mod de viaţă, [Creativity as a Lifestyle] Bucureşti: Editura Ştiință şi Tehnică.

Aven, F., DeVries, P., Williams, D. G. \& Smith, Ch. (2002). Inambiguity tolerance in entrepreneurs of micro-enterprises, Journal of Business and Entrepreneurship, October, 14(2) http://www.questia.com/read/1P31399954241/intolerance-of-ambiguity-in-entrepreneurs-of-microenterprises

Balgiu, B. A. (2012). Tolerance for ambiguity and creativity. Research on Romanian students at the Polytechnic University. Romanian Journal of School Psychology, 5(9), 63 - 74.

Boyd, V. S., Hunt, P. F., Kandell, J. J., \& Lucas, M. S. (2003). Relationship between identity processing style and academic success in undergraduate students. Journal of College Student Development, 44(2), $155-167$.

Comadena, M. E. (1984). Brainstorming groups: ambiguity tolerance, communication, apprehension, task attraction, and individual productivity. Small Group Behavior, 15(2), 251 - 264.

Durrheim, K., \& Foster, D. (1997). Ambiguity tolerance as a content specific construct. Personality and Individual Differences, 22(5), $741-750$.

Furnham, A., \& Marks, J. (2013) Ambiguity tolerance: A review of the recent literature. Psychology, 4(9), $717-728$.

Heilbrun, B. (2002). Logo-ul, [The logo]. Bucureşti: Editura comunicare.ro.

Helmick, A. B. (1982). Two cognitive styles among library science students: fielddependence/independence and tolerance-intolerance for ambiguity, Thesis (PhD) Florida State University, Published by University Microfilms International in Ann Arbor Mich.

Johns, G. (1998). Comportament organizational, [Organizational behaviour]. Bucureşti: Editura Economică.

Judge, T. A., Thoresen, C. J., Pucik, V., \& Welbourne, T. M. (1999). Managerial coping with organizational change: A dispositional perspective. Journal of Applied Psychology, 84, 107-122.

Kajs, L. T., \& McCollum, D. L. (2009). Examining tolerance for ambiguity in the domain of educational leadership. Academy of Educational Leadership Journal, 13(2), 1 - 16. 
Lauriola, M., \& Levin, I. P. (2001). Relating individual differences in attitude toward ambiguity to risky choices. Journal of Behavioral Decision Making, 14(2), $107-122$.

Lubart, T. I. (1994). Creativity. In R. J. Sternberg, (ed.) Thinking and problem solving. New York: Academic Press.

McCulloch, P., Kaul, A., Wagstaff, G. F., \& Wheatcroft, J. (2005). Tolerance of uncertainty, extroversion, neuroticism and attitudes to randomized controlled trials among surgeons and physicians. British Journal of Surgery, 92(10), 1293 - 1297.

Nutt, P. C. (1988). The tolerance for ambiguity and decision making. Columbus Ohio, The Ohio state University, College of Bussiness Working Paper Series.

Pürto, J. (2004). Understanding creativity. Scottsdale, AZ Great Potential Press.

Radant, M. (2008). The dimensions of the complexity tolerance: a sinopsis of personality construct, (unpublished communication), XXIX International Congress of Psychology, Berlin, 20 - 25 iulie 2008.

Sherrill, W. W. (2001). Ambiguity tolerance among MD/MBA students: implications for management potential. Journal of Continuing Education in the Health Professions, 21(2), $117-122$.

Sternberg, R. J., \& Lubart, T. I. (1995). Investing in creativity. American Psychologist, 51(7), 677 - 688.

Stoica-Constantin, A., \& Caluschi, M. (1989). Ghid practic de evaluare a creativității, [Practical Guide for the Assessment of Creativity]. Iaşi, Universitatea Al. I. Cuza, 163.

Stoica-Constantin, A., \& Caluschi, M. (2006). Evaluarea creativităţii. Ghid practic, [Assessment of Creativity. Practical Guide]. Iaşi: Editura Performantica, 107.

Stoycheva, K. (2003). Talent, science and education: How do we cope with uncertainty and ambiguities? In P. Csermely, L. Lederman (eds.), Science education: Talent recruitment and public understanding, Nato Science Series V/38. Amsterdam: IOS press, $31-33$.

Stoycheva, K. (2008). The new and the best: ambiguity tolerance and creativity motivation, (unpublished communication), XXIX International congress of psychology, Berlin, 20 - 25 iulie 2008.

Stoycheva, K. (2009). Tolerance for ambiguity, creativity and personality, http://eprints.nbu.bg/1705/1/SEERCP2009 Katya\%20Stoycheva.pdf

Stoycheva, K., Popova, K., \& Komneva, K. (2007). Creative problem solving: problem redefinition and generation of creative solutions. Yearbook of the Department of Cognitive Science and Psychology of the New Bulgarian University, $17-31$.

Thompson, J. E., Austin, J. S., \& Walters, B. A. (2004). The relationship between tolerance for ambiguity and students propensity to cheat on a college exam. Journal of College Teaching and Learning, 1(1), 63 - 72 
http://journals.cluteonline.com/index.php/TLC/article/view/1904/18 $\underline{83}$

Urban, K. (2003). Toward a componential model of creativity. In D. Ambrose, L. M. Cohen \& A.J. Tannenbaum (Eds.). Creative Intelligence: Toward Theoretic Integration. Cresskill, NJ: Hampton Press Inc.

Vernon, P. E. (1970). Creativity: selected readings. Middlesex: Penguin.

Zenasni, F., Besançon, M., \& Lubart, T. (2008). Creativity and ambiguity tolerance: an empirical study. Journal of creative behavior, 42(1), $61-73$. 